\title{
Platinum, palladium, and rhodium deposition to the Prunus laurus cerasus leaf surface as an indicator of the vehicular traffic pollution in the city of Varese area
}

\author{
An easy and reliable method to detect PGEs released from automobile catalytic \\ converters
}

Alessandro Fumagalli • Bruno Faggion •

Matteo Ronchini • Giorgio Terzaghi •

Marco Lanfranchi $\cdot$ Nicola Chirico $\cdot$ Laura Cherchi

Received: 26 February 2009 / Accepted: 26 April 2009

(C) Springer-Verlag 2009

\begin{abstract}
Background, aim, and scope The widespread use of some platinum group elements as catalysts to minimize emission of pollutants from combustion engines produced a constantly growing increase of the concentration of these elements in the environment; their potential toxicological properties explain the increasing interest in routine easy monitoring. We have found that leaves of Prunus laurus cerasus are efficient collectors of particulate with a dimension $<60$ $80 \mu \mathrm{m}$, and a simple and reliable procedure was developed to reveal traces of platinum, palladium, and rhodium released from automotive catalysts. The analysis of the dust deposited on the foliage is a direct indicator of traffic pollution.

Materials and methods Leaves of P. laurus cerasus were washed by sonication in a mixture of water and 2-propanol and the washings, to be discarded, were separated by centrifugation to yield typically $0.05-1.2 \mathrm{~g}$ of dust that, after mineralization, was directly submitted for atomic absorption analysis.

Results Comparison of the 2007 and 2004-2005 results showed a dramatic reduction of the platinum levels and revealed that palladium is now the main component of this traffic-related pollution.

Discussion The results are consistent with the increasing diffusion of cars with a diesel engine whose catalysts are
\end{abstract}

A. Fumagalli $(\bowtie) \cdot$ B. Faggion $\cdot$ M. Ronchini $\cdot$ G. Terzaghi $\cdot$

M. Lanfranchi $\cdot$ N. Chirico $\cdot$ L. Cherchi

Dipartimento di Biologia Strutturale e Funzionale,

Università dell'Insubria,

Via J. H. Dunant,

321100 Varese, Italy

e-mail: alessandro.fumagalli@uninsubria.it made up of $\mathrm{Pt}$ and/or Pd alone, and gives a significant insight into the recent evolution in catalyst design that replaces platinum for palladium.

Conclusions The proposed analytical procedure is simple, with short preparation times, and greatly reduces matrix effects so that atomic absorption spectroscopy can easily detect the three noble metals at the ng/g level in the dust. Recommendation and perspectives The results clearly show that Pd concentrations have increased over time, and must be cause for concern.

Keywords Atomic absorption - Automobile catalysts . Foliage uptake - GFAA · Metal pollution · Palladium · PGE · Platinum group elements $\cdot$ Platinum $\cdot$ Prunus laurus cerasus $\cdot$ Rhodium $\cdot$ Road dust $\cdot$ Traffic pollution $\cdot$ Varese

\section{Background, aim, and scope}

Since the beginning of the 1980s, the widespread use of some platinum group elements (PGE) as catalysts to minimize emission of pollutants from combustion engines produced a slow but constantly growing increase in the concentration of these elements in the environment (Zereini and Alt 1999). During this time period, the auto catalysts have progressed through many development phases and have been tailored upon different engines. Thus, different devices have been developed, from those based on platinum alone to combinations of Pt-Rh, Pd-Rh, Pt-Pd-Rh, and Pd alone (Heck and Farrauto 2001). The three metals platinum, 
palladium, and rhodium are released with catalyst aging, essentially as metal particles bonded to fragments of the ceramic support (Moldovan et al. 2002), as a consequence of surface abrasion during car operation. Sometimes they have been detected as oxides and even as soluble chloro-complexes (Palacios et al. 2000; Gomez et al. 2002). Toxicological data available so far are relative to soluble compounds of $\mathrm{Pt}(\mathrm{II}), \mathrm{Pt}$ (IV), Pd(II), Pd(IV), Rh(III), and Rh(II) essentially as chlorocomplexes (Bikhazi et al. 1995; Gebel et al. 1997; Merget and Rosner 2001). Bioaccumulation of PGEs has been shown to possibly be influenced by the presence of complexing agents (Zimmerman et al. 2003); in organisms such as Asellus aquaticus (Moldovan et al. 2001), it depends upon the exposition time. Remarkably, a recent paper stressed the possible role of PGEs in the formation of free radicals (Botrè et al. 2007). The potential toxicological properties of PGE explain the increasing interest in routine easy monitoring.

Our studies started in 2002 with a preliminary survey directed toward analysis of road dust; typically, the samples were collected over a $1-\mathrm{m}^{2}$ surface by means of a pure bristle brush, and then sifted through a $<0.05-\mathrm{mm}$ sieve. To evaluate a possible retention of PGEs by the plants, we also examined a few plant samples and we soon decided to restrict our investigation to the leaves of Prunus laurus cerasus because of its almost ubiquitous presence in the northern Italian urban environment and its evergreen nature that allows round-the-year samplings. An additional remarkable feature is that these leaves act as passive collectors of particulate matter (PM), like a sheet of fly paper. In fact, the waxed surface collects, mostly on the upper side, dust from a maximum of ca. $60-80 \mu \mathrm{m}$ down to the very minute PM (Giovannardi 2008, personal communication - an observation made with a confocal microscope; $60-80 \mu \mathrm{m}$ is the maximum size of the granules stuck on the upper page of a leaf of $P$. laurus cerasus; the lower side holds a minor fraction of particulate made of even smaller granules), an efficient size selection comparable to that performed by means of a sieve. The dust recovery was then easily performed with sonication in water (with some 2-propanol added as a wetting agent) that suitably cleans the leaf surface.

For each sampling location, we therefore compared the results from four types of samples: (1) the sifted road dust, (2) the dirty leaves, (3) the cleaned ones, and (4) the foliar dust recovered from the washings. In cases (2) and (3), the leaves, prior to the mineralization process, were dried and then incinerated at $800^{\circ} \mathrm{C}$ for $3-4 \mathrm{~h}$. Mineralization was applied, with some variation, to all the samples (as described below) to obtain the solutions that, analyzed by atomic absorption, allowed the detection of the three PGEs at a level of $\mu \mathrm{g} / \mathrm{l}$ translating, with reference to the original samples, in a few $\mathrm{ng} / \mathrm{g}$. In this first phase of the investigation, many analyses were made with the standard addition methods to overcome possible matrix effects. Actually, all the plant samples gave a large matrix effect, which often severely hindered reliable results. In a few cases, filtration of the solutions (through a C18 packed reversed-phase column) was experimented; these samples showed a better instrumental signal with some reduction of the matrix effects though, particularly the samples with the lowest content of metals, they also exhibited a systematic retention of analyte. In any case, the results obtained with the washed leaves revealed amounts of the three platinoids under the instrumental detection limits (IDL). Thus, we retained this as a proof that the three metals are essentially present in the particulate deposited on the surface, with no significant absorption by the leaves. Tests to evaluate the efficiency of the recovery were also tried by addition of standard solution of the three metals or of a certified NIST standard obtained from milled auto catalyst (see experimental); the plant samples were doped in this way prior to the incineration step. The recovery was generally better than $80 \%$.

At the end of these sets of experiments, we could deduce that only the dust samples, particularly those retained by the leaf surface, could be the realistic object of a study on the PGE pollution in urban environment.

\section{Materials and methods}

\subsection{Analysis of the foliar dust}

\subsubsection{Sampling sites}

On the basis of our preliminary results, we decided to focus only on the particulate matter (PM) collected by the leaf surface of the species P. laurus cerasus. With reference to the map in Fig. 1, monthly samples were collected during two periods, October 2004-May 2005 and JanuarySeptember 2007 (hereafter indicated briefly as 2004-2005 and 2007), at four sites characterized by major vehicular traffic; two of these locations were chosen along viale Borri, the urban section of SS233 (Strada Statale, a state road), nearby Istituto Molina (Borri-Molina, Bm), and at the intersection with Via Valmorea (Borri-Valmorea, Bv). In this second site, leaves were collected also at ca. $20 \mathrm{~m}$ from the main traffic flux of viale Borri, inside via Valmorea (Bvi). A third location was chosen at the intersection of Via Virgilio with Via Molini Grassi $(\mathrm{Mg})$ and the fourth one at the Rotonda di Gazzada (Gz), a great intersection of SP57 (Strada Provinciale, a county road) out of the city limits of Varese and connected to the highway. The traffic fluxes in the three town sites can be somewhat estimated from an official report (Comune di Varese, Ufficio Tecnico Traffico e Trasporti 2003): in the peak hours (7:30-8:30 and 17:30- 


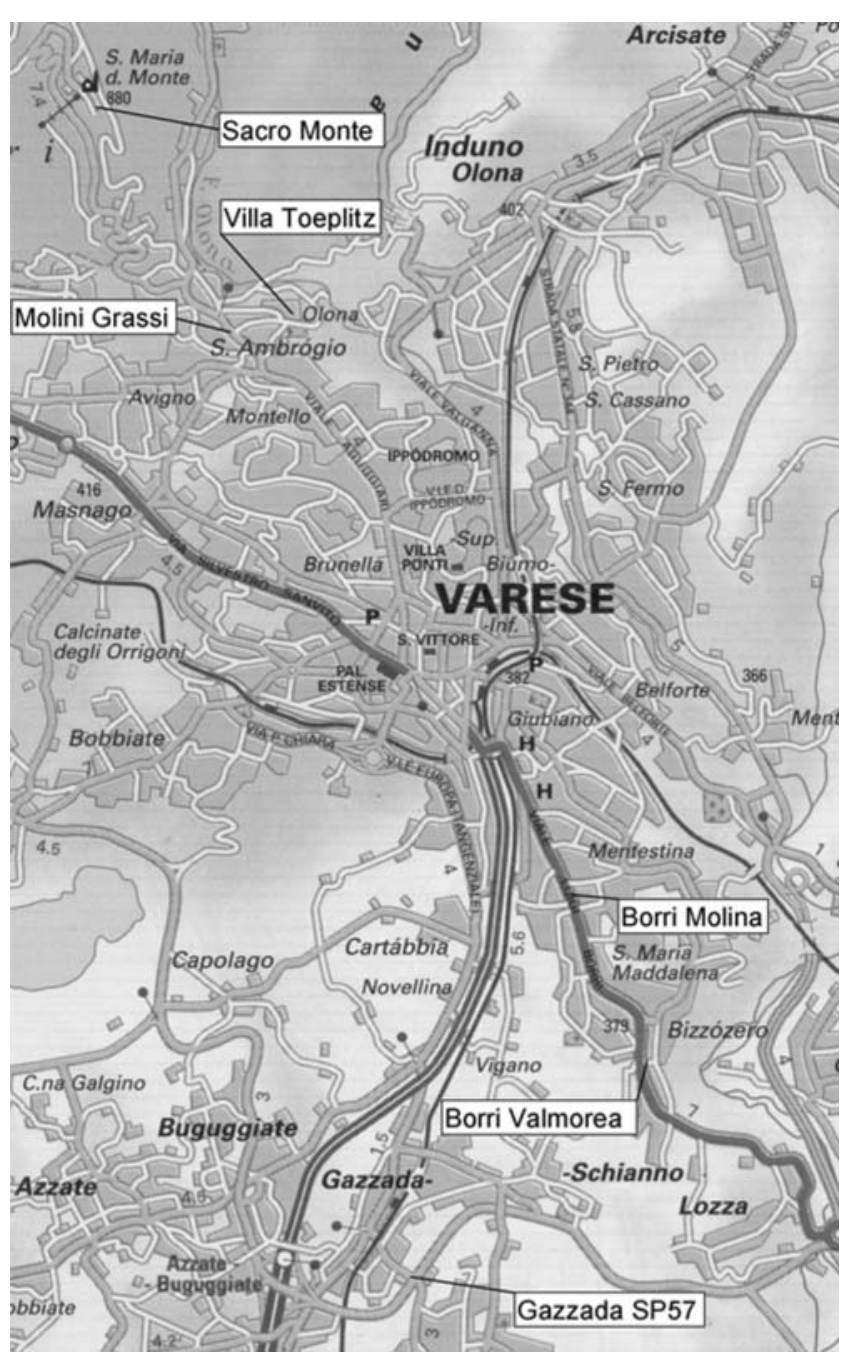

Fig. 1 A map of the city of Varese and a part of its surrounding area, showing the location of the six sampling sites

18:30), approximately 4,500 motor vehicles pass Viale Borri, while in via Virgilio-Aguggiari, close to the Mg site, they may be approximately 2,500 . The site Gz is substantially different from the previous ones because of the transit of many heavy vehicles; according to recent data (Provincia di Varese, http://www.provincia.va.it/viabilita.htm), in an average day of January 2008, more than 4,000 trucks (ca. $15 \%$ ) were counted from a total of 28,000 vehicles.

As a reference for minimal exposure to the traffic pollution, we chose the site of Villa Toeplitz (To, within a city park and approximately $500 \mathrm{~m}$ from the heavy traffic of $\mathrm{Mg}$ ) and in 2007, regular samplings began also at Sacro Monte (Sm), a small traffic-restricted neighborhood of Varese, on the top of a hill. In the following, we will discuss in detail the more recent data very indicative to define the levels of traffic pollution. The previously obtained data (2004-2005) will then be taken into account to evidence temporal trends.

\subsubsection{Sample treatment}

Samples of leaves, typically 40-50 g (fresh weight, FW), were collected at each site once a month, picking up the old and the new leaves randomly between 0.5 and $1.5 \mathrm{~m}$ above the ground (see Section 3.2) and, when possible, at least 10-15 days after any heavy raining event.

All the chemicals used for the sample pre-treatments and mineralization were for metal trace analysis (or equivalent) grade: water was purified using a Milli-Q water system (Millipore); 2-propanol (Fluka 59300); hydrochloric acid (Baker 9530 for metal trace analysis, 36.5-38\%); nitric acid (Baker 9598 for metal trace analysis, 69-70\%); hydrogen peroxide (Fluka 95313, not stabilized, 30\%). Calibration standard solutions were prepared daily from $1,000 \mathrm{mg} / \mathrm{l}$ standard solutions of Pt, Pd, or Rh purchased from J. T. Baker Instra-Analyzed. A reference standard, made from milled auto catalyst (NIST, standard reference material 2556, used auto catalyst pellets), with a certified content of $\mathrm{Pt}$, $\mathrm{Pd}$, and $\mathrm{Rh}$ $(697.4,326$, and $51.2 \mathrm{mg} / \mathrm{kg}$, respectively) was used to evaluate trueness; results generally showed a recovery within the limits of SD.

The sample treatments can be summarized as follows:

(a) Recovery of the dust stuck on the leaves - the leaves (ca. $40 \mathrm{~g}, \mathrm{FW}$ ), contained in an Erlenmeyer flask, were submersed with a mixture of water and 2-propanol (3:1, ca. 200-250 ml) and sonicated for $1 \mathrm{~h}$. The 'cleaned' leaves were taken off with Teflon-covered tweezers and discarded or, if the case, treated as below at point (b). It must be pointed out that the washing must be as short as possible, since the solvent mixture may extract some unwanted stuff from the leaves. At the beginning of our study, the precipitated-suspended dust was simply recovered by evaporation of the solution on a hot plate; in those conditions, the samples retained all the material possibly solubilized in the washing procedure (typical in this regard is the winter de-icing salt). Based on the assumption that the particulate matter we were looking for is insoluble in the solvent mixture (this was proved with the standard from used auto catalyst as mentioned above), we devised an alternative method. Thus, in the second period of our survey (2007), we experimented with the centrifugation (in $250-\mathrm{ml}$ bottles at 5,000 rpm, 20', in a Sorvall GSA rotor) as a method for easy separation of most of the washing solvent that was discarded as a clear supernatant. Only a minor residual fraction of the solvent was then evaporated on a hot plate to typically yield $0.05-1.2 \mathrm{~g}$ of dust. It must be noted that this procedure not only considerably saves time but greatly reduces interferences from matrix effects on the subsequent AA analysis. 
(b) Leaves - the leaves, typically $40 \mathrm{~g}$ (as collected, or with the dust removed as described above), were dried in an oven at $110^{\circ} \mathrm{C}$ overnight and then incinerated in a large porcelain crucible at $800^{\circ} \mathrm{C}$ for $3 \mathrm{~h}$.

(c) Mineralization-dust or ashes, obtained as above, were at first digested with hydrochloric acid and hydrogen peroxide (6 and $8 \mathrm{ml}$, respectively, added in several small portions), till evidence of complete decomposition of the organic matter (the thick foam subsides); the samples were evaporated to incipient dryness on a hotplate and then treated with aqua regia (a mixture of concentrated nitric acid and hydrochloric acid of 1:3, 2 and $6 \mathrm{ml}$, respectively). The sample was again cautiously almost reduced to dryness and, after addition of some $\mathrm{HCl}(0.25-1 \mathrm{ml}$, to reach a final content of approximately $1 \%$ ), transferred in a suitable volumetric flask $(25-100 \mathrm{ml})$ making up the volume with Milli-Q water. It must be said, after this procedure, that a precipitate was generally present on the bottom of the volumetric flask. In any case, atomic absorption analyses were performed on the clear decanted aqueous solutions. Blanks were made with the same solvents and chemicals employed in the treatment and digestion of the samples, or with just $1 \%$ hydrochloric acid in Milli-Q water. The certified standard from used auto catalyst was used to check the reliability of our procedure. Thus, in a few tests, $1-2 \mathrm{mg}$ of this standard (exactly weighted, with $0.01 \mathrm{mg}$ accuracy), suspended in the washing mixture, underwent the above-described procedure; recovery was generally better than $80 \%$.

\subsubsection{Atomic absorption spectrophotometry}

Measurements were performed on a Thermo-Electron atomic absorption spectrometer: $\mathrm{Pt}, \mathrm{Pd}$, and $\mathrm{Rh}$, at $\mathrm{ng} / \mathrm{ml}$ (ppb) levels, were determined by graphite furnace (GFAA) coupled with Zeeman background correction. Thermal ramps with double drying and ashing steps were specifically developed, according to Table 1.
Wavelength, bandpass, and all other instrumental parameters were set according to the usual recommendations of the instrument Cookbook.

\subsection{Data treatment}

The reported analytical results (actual concentration, in $\mathrm{ng} / \mathrm{ml}$ ) are the mean of three measurements with their inherent $\sigma$. Conventional instrumental detection limits (IDL, based on three standard deviations of the blank signal), were calculated at each monthly run for each analyzed element. On this basis, three categories of data values were considered: (1) fully significant ones, above the IDL, (2) values $<$ IDL, ranging within $3 \sigma$ blank (IDL) and $1 \sigma$ blank (marked in Table 2 in italics), and (3) values $<1 \sigma$ of the blank that were marked 'nd' (not detected, virtually 'zero' concentration). A few values $<\mathrm{IDL}$, but having an inherent $\sigma>$ IDL, were discarded.

Evaluating and discussing the data, along with mean values, we also considered the median as a representative index. In these latter cases, with uneven data amounts, the median value was extracted as usual. If a data amount was even with the two central data belonging to the same category (see above), the mean was calculated as usual (in the event of two "nd", the result was only "nd"). If the mean had to be calculated with data values of two different categories, we selected the most reliable one. For example, with a value $>$ IDL and the other $<$ IDL, we simply chose the first one.

The results of the 2007 survey are reported in Table 2 with the $\mathrm{Pt}, \mathrm{Pd}$, and $\mathrm{Rh}$ showing amounts in $1 \mathrm{~g}$ of fresh weighed leaves collected at a specific site (ng/g FW leaf) and the concentrations of the three metals in the particulate matter (ng/g PM).

\section{Results and discussion}

\subsection{Influence of the atmospheric precipitations}

The average fresh weight (FW) of one P. laurus cerasus leaf is around $1 \mathrm{~g}$ and the surface (of one page) has been

Table 1 Thermal ramps for GFAA

\begin{tabular}{|c|c|c|c|c|c|c|c|c|c|}
\hline & \multicolumn{3}{|l|}{$\mathrm{Pt}$} & \multicolumn{3}{|l|}{$\mathrm{Pd}$} & \multicolumn{3}{|l|}{$\mathrm{Rh}$} \\
\hline & Temp $\left({ }^{\circ} \mathrm{C}\right)$ & Time (s) & $\operatorname{Ramp}\left({ }^{\circ} \mathrm{C} / \mathrm{s}\right)$ & Temp $\left({ }^{\circ} \mathrm{C}\right)$ & Time (s) & $\operatorname{Ramp}\left({ }^{\circ} \mathrm{C} / \mathrm{s}\right)$ & Temp $\left({ }^{\circ} \mathrm{C}\right)$ & Time (s) & $\operatorname{Ramp}\left({ }^{\circ} \mathrm{C} / \mathrm{s}\right)$ \\
\hline \multirow[t]{2}{*}{ Drying } & 90 & 5 & 5 & 95 & 5 & 5 & 95 & 5 & 10 \\
\hline & 115 & 20 & 2 & 115 & 30 & 3 & 115 & 20 & 2 \\
\hline \multirow[t]{2}{*}{ Ashing } & 800 & 5 & 50 & 800 & 1 & 25 & 800 & 5 & 25 \\
\hline & 1,200 & 30 & 100 & 1,100 & 45 & 100 & 1,300 & 20 & 50 \\
\hline Atomization & 2,500 & 3 & 0 & 2,200 & 3 & 0 & 2,800 & 3 & 0 \\
\hline Cleaning & 2,600 & 6 & 0 & 2,500 & 3 & 0 & 2,900 & 6 & 0 \\
\hline
\end{tabular}

Note the double drying and ashing steps 
Table 2 Results of the January-September 2007 period

\begin{tabular}{|c|c|c|c|c|c|c|c|c|c|c|c|c|}
\hline \multirow[t]{2}{*}{ Site } & \multirow[t]{2}{*}{ Date } & \multirow[t]{2}{*}{ Leaf (FW g) } & \multirow[t]{2}{*}{ PM (g) } & \multicolumn{3}{|c|}{ Actual concentrations (ng/ml) } & \multicolumn{3}{|c|}{$\begin{array}{l}\text { Leaf collected PGE } \\
\text { (ng/g FW leaf) }\end{array}$} & \multicolumn{3}{|c|}{$\begin{array}{l}\text { PM composition } \\
\text { (ng/g PM) }\end{array}$} \\
\hline & & & & $\mathrm{Pt}$ & $\mathrm{Pd}$ & $\mathrm{Rh}$ & $\mathrm{Pt}$ & $\mathrm{Pd}$ & $\mathrm{Rh}$ & $\mathrm{Pt}$ & $\mathrm{Pd}$ & $\mathrm{Rh}$ \\
\hline $\mathrm{Bm}$ & jan-07 & 48.641 & 1.072 & $1.36 \pm 0.38$ & $5.30 \pm 0.33$ & $1.16 \pm 0.18$ & 1.40 & 5.45 & 1.19 & 63.6 & 247 & 53.9 \\
\hline $\mathrm{Bv}$ & jan-07 & 56.279 & 0.400 & $0.25 \pm 0.19$ & $3.49 \pm 0.57$ & $0.50 \pm 0.23$ & 0.22 & 3.10 & 0.45 & 31.1 & 437 & 63.0 \\
\hline Bvi & jan-07 & 49.068 & 0.906 & nd & - & nd & nd & - & nd & nd & - & nd \\
\hline $\mathrm{Gz}$ & jan-07 & 57.339 & 0.691 & $0.40 \pm 0.27$ & $3.59 \pm 1.03$ & $0.59 \pm 0.22$ & 0.35 & 3.13 & 0.51 & 29.1 & 260 & 42.4 \\
\hline $\mathrm{Mg}$ & jan-07 & 53.018 & 1.190 & $0.12 \pm 0.08$ & $6.14 \pm 0.98$ & $0.92 \pm 0.02$ & 0.12 & 5.79 & 0.87 & 5.1 & 258 & 38.6 \\
\hline $\mathrm{Sm}$ & jan-07 & 52.293 & 0.165 & $0.11 \pm 0.04$ & nd & nd & 0.11 & nd & nd & 34.2 & nd & nd \\
\hline To & jan-07 & 50.849 & 0.924 & nd & $2.19 \pm 0.83$ & nd & nd & 2.15 & nd & nd & 119 & nd \\
\hline IDL & jan-07 & & & 0.36 & 2.66 & 0.68 & & & & & & \\
\hline $\mathrm{Bm}$ & feb-07 & 48.641 & 1.130 & $1.85 \pm 0.28$ & $4.09 \pm 2.39$ & $2.93 \pm 0.90$ & 0.95 & 2.10 & 1.51 & 40.9 & 90.6 & 64.8 \\
\hline $\mathrm{Bv}$ & feb-07 & 56.279 & 1.146 & $2.69 \pm 0.79$ & $2.08 \pm 0.60$ & $1.61 \pm 0.81$ & 1.19 & 0.92 & 0.71 & 58.7 & 45.4 & 35.1 \\
\hline Bvi & feb-07 & 49.068 & 0.417 & $3.88 \pm 0.93$ & $10.05 \pm 0.62$ & $0.57 \pm 0.34$ & 1.98 & 5.12 & 0.29 & 233 & 603 & 34.3 \\
\hline $\mathrm{Gz}$ & feb-07 & 57.339 & 1.292 & $3.98 \pm 0.88$ & $2.36 \pm 0.36$ & $3.23 \pm 0.70$ & 1.74 & 1.03 & 1.41 & 77.1 & 45.7 & 62.5 \\
\hline $\mathrm{Mg}$ & feb-07 & 49.345 & 0.867 & $4.04 \pm 1.03$ & $2.53 \pm 0.62$ & $3.05 \pm 0.71$ & 2.05 & 1.28 & 1.55 & 117 & 72.9 & 88.0 \\
\hline $\mathrm{Sm}$ & feb-07 & 53.119 & 0.068 & $0.99 \pm 0.31$ & nd & $0.34 \pm 0.09$ & 0.47 & nd & 0.16 & 364 & nd & 127 \\
\hline To & feb-07 & 47.394 & 0.168 & nd & $1.34 \pm 1.05$ & $0.26 \pm 0.10$ & nd & 0.71 & 0.14 & nd & 200 & 39.1 \\
\hline IDL & feb-07 & & & 2.34 & 0.87 & 0.72 & & & & & & \\
\hline $\mathrm{Bm}$ & mar-07 & 48.811 & 0.858 & $2.37 \pm 0.68$ & $4.57 \pm 0.12$ & $4.19 \pm 0.20$ & 1.22 & 2.34 & 2.15 & 69.1 & 133 & 122 \\
\hline $\mathrm{Bv}$ & mar-07 & 52.242 & 1.183 & nd & $2.01 \pm 0.60$ & $2.91 \pm 0.51$ & nd & 0.96 & 1.39 & nd & 42.4 & 61.5 \\
\hline Bvi & mar-07 & 40.500 & 0.396 & - & nd & nd & - & nd & nd & - & nd & nd \\
\hline $\mathrm{Gz}$ & mar-07 & 56.741 & 1.201 & $0.95 \pm 0.37$ & $2.83 \pm 0.98$ & $2.70 \pm 0.63$ & 0.42 & 1.25 & 1.19 & 19.7 & 59.0 & 56.1 \\
\hline $\mathrm{Mg}$ & mar-07 & 48.684 & 0.656 & nd & $3.88 \pm 0.98$ & $2.16 \pm 0.88$ & nd & 1.99 & 1.11 & nd & 148 & 82.3 \\
\hline $\mathrm{Sm}$ & mar-07 & 52.521 & 0.098 & nd & - & nd & nd & - & nd & nd & - & nd \\
\hline To & mar-07 & 53.389 & 0.049 & nd & $1.08 \pm 1.59$ & $0.53 \pm 0.71$ & nd & 0.50 & 0.25 & nd & 547 & 267 \\
\hline IDL & mar-07 & & & 1.39 & 3.14 & 0.84 & & & & & & \\
\hline $\mathrm{Bm}$ & apr-07 & 50.686 & 0.988 & $2.27 \pm 0.38$ & $11.87 \pm 1.44$ & $3.61 \pm 0.54$ & 1.12 & 5.85 & 1.78 & 57.6 & 300 & 91.3 \\
\hline $\mathrm{Bv}$ & apr-07 & 52.300 & 0.585 & nd & $2.63 \pm 0.53$ & $1.65 \pm 0.61$ & nd & 1.26 & 0.79 & nd & 113 & 70.5 \\
\hline Bvi & apr-07 & 45.586 & 0.411 & - & nd & nd & - & nd & nd & - & nd & nd \\
\hline $\mathrm{Gz}$ & apr-07 & 56.644 & 1.200 & $1.13 \pm 0.59$ & $5.82 \pm 1.56$ & $4.66 \pm 0.46$ & 0.50 & 2.57 & 2.06 & 23.6 & 121 & 97.1 \\
\hline $\mathrm{Mg}$ & apr-07 & 48.693 & 0.984 & $1.78 \pm 0.04$ & $7.10 \pm 0.18$ & $4.64 \pm 0.42$ & 0.91 & 3.65 & 2.38 & 45.2 & 180 & 118 \\
\hline $\mathrm{Sm}$ & apr-07 & 51.957 & 0.744 & nd & $1.72 \pm 1.06$ & $0.56 \pm 0.20$ & nd & 0.83 & 0.27 & nd & 57.9 & 19.0 \\
\hline To & apr-07 & 56.122 & 0.315 & nd & $0.96 \pm 0.34$ & $1.39 \pm 0.60$ & nd & 0.43 & 0.62 & nd & 76.6 & 111 \\
\hline IDL & apr-07 & & & 1.55 & 0.56 & 0.66 & & & & & & \\
\hline $\mathrm{Bm}$ & may-07 & 42.987 & 0.152 & $1.36 \pm 0.26$ & $3.52 \pm 1.05$ & $2.68 \pm 0.09$ & 0.79 & 2.04 & 1.56 & 225 & 580 & 442 \\
\hline $\mathrm{Bv}$ & may-07 & 48.378 & 0.558 & nd & $1.84 \pm 0.40$ & $1.17 \pm 0.76$ & nd & 0.95 & 0.61 & nd & 82.3 & 52.4 \\
\hline Bvi & may-07 & 50.463 & 0.576 & nd & nd & $0.79 \pm 1.29$ & nd & nd & 0.39 & nd & nd & 34.3 \\
\hline $\mathrm{Gz}$ & may-07 & 51.773 & 0.478 & $1.38 \pm 0.32$ & $6.34 \pm 0.53$ & $3.85 \pm 0.23$ & 0.67 & 3.06 & 1.86 & 72.3 & 331 & 201 \\
\hline $\mathrm{Mg}$ & may-07 & 45.358 & 0.434 & nd & $4.52 \pm 1.12$ & $1.67 \pm 0.37$ & nd & 2.49 & 0.92 & nd & 261 & 96.3 \\
\hline $\mathrm{Sm}$ & may-07 & 57.727 & 0.174 & nd & nd & $0.52 \pm 0.23$ & nd & nd & 0.22 & nd & nd & 74.3 \\
\hline To & may-07 & 55.064 & 0.215 & nd & nd & $1.63 \pm 0.73$ & nd & nd & 0.74 & nd & nd & 190 \\
\hline IDL & may-07 & & & 2.51 & 1.94 & 0.34 & & & & & & \\
\hline $\mathrm{Bm}$ & jun-07 & 48.559 & 0.356 & $0.21 \pm 0.06$ & $3.35 \pm 1.19$ & $4.44 \pm 0.42$ & 0.11 & 1.73 & 2.28 & 14.5 & 236 & 312 \\
\hline $\mathrm{Bv}$ & jun-07 & 52.478 & 0.985 & $0.72 \pm 0.10$ & $5.25 \pm 0.54$ & $5.00 \pm 0.57$ & 0.34 & 2.50 & 2.38 & 18.2 & 133 & 127 \\
\hline Bvi & jun-07 & 43.596 & 0.475 & - & $1.37 \pm 0.49$ & $1.39 \pm 2.60$ & - & 0.78 & 0.80 & - & 71.9 & 73.0 \\
\hline $\mathrm{Gz}$ & jun-07 & 56.725 & 1.248 & $2.55 \pm 0.23$ & $3.49 \pm 0.30$ & $6.38 \pm 0.71$ & 1.13 & 1.54 & 2.81 & 51.2 & 69.8 & 128 \\
\hline $\mathrm{Mg}$ & jun-07 & 48.861 & 1.086 & $1.63 \pm 0.41$ & $4.08 \pm 1.28$ & $9.01 \pm 0.49$ & 0.83 & 2.09 & 4.61 & 37.5 & 93.9 & 207 \\
\hline $\mathrm{Sm}$ & jun-07 & 52.379 & 0.102 & - & $1.29 \pm 0.56$ & $1.44 \pm 2.98$ & - & 0.62 & 0.69 & - & 318 & 353 \\
\hline
\end{tabular}


Table 2 (continued)

\begin{tabular}{|c|c|c|c|c|c|c|c|c|c|c|c|c|}
\hline \multirow[t]{2}{*}{ Site } & \multirow[t]{2}{*}{ Date } & \multirow[t]{2}{*}{ Leaf (FW g) } & \multirow[t]{2}{*}{$\mathrm{PM}(\mathrm{g})$} & \multicolumn{3}{|c|}{ Actual concentrations (ng/ml) } & \multicolumn{3}{|c|}{$\begin{array}{l}\text { Leaf collected PGE } \\
\text { (ng/g FW leaf) }\end{array}$} & \multicolumn{3}{|c|}{$\begin{array}{l}\text { PM composition } \\
\text { (ng/g PM) }\end{array}$} \\
\hline & & & & $\mathrm{Pt}$ & $\mathrm{Pd}$ & $\mathrm{Rh}$ & $\mathrm{Pt}$ & $\mathrm{Pd}$ & $\mathrm{Rh}$ & $\mathrm{Pt}$ & $\mathrm{Pd}$ & $\mathrm{Rh}$ \\
\hline To & jun-07 & 55.130 & 0.192 & nd & $1.30 \pm 0.22$ & $1.69 \pm 2.18$ & nd & 0.59 & 0.77 & nd & 169 & 220 \\
\hline IDL & jun-07 & & & 0.20 & 2.70 & 3.50 & & & & & & \\
\hline $\mathrm{Bm}$ & jul-07 & 48.487 & 0.508 & $0.64 \pm 0.06$ & $8.38 \pm 1.28$ & $0.72 \pm 0.13$ & 0.33 & 4.32 & 0.37 & 31.5 & 413 & 35.6 \\
\hline $\mathrm{Bv}$ & jul-07 & 51.735 & 0.550 & $0.76 \pm 0.11$ & $2.31 \pm 0.49$ & $0.53 \pm 0.08$ & 0.37 & 1.12 & 0.26 & 34.4 & 105 & 24.2 \\
\hline Bvi & jul-07 & 39.186 & 1.626 & nd & nd & nd & nd & nd & nd & nd & nd & nd \\
\hline $\mathrm{Gz}$ & jul-07 & 47.224 & 0.570 & $2.16 \pm 0.96$ & $3.17 \pm 0.61$ & $1.36 \pm 0.08$ & 1.15 & 1.68 & 0.72 & 94.9 & 139 & 59.8 \\
\hline $\mathrm{Mg}$ & jul-07 & 44.602 & 0.582 & $1.65 \pm 0.25$ & $4.48 \pm 0.23$ & $1.26 \pm 0.12$ & 0.92 & 2.51 & 0.70 & 70.8 & 192 & 54.0 \\
\hline $\mathrm{Sm}$ & jul-07 & 52.369 & 0.361 & nd & nd & $0.33 \pm 0.04$ & nd & nd & 0.16 & nd & nd & 23.1 \\
\hline To & jul-07 & 53.660 & 0.274 & nd & $3.66 \pm 0.35$ & $1.50 \pm 0.10$ & nd & 1.70 & 0.70 & nd & 334 & 137 \\
\hline$I D L$ & jul-07 & & & 1.13 & 2.27 & 0.88 & & & & & & \\
\hline $\mathrm{Bm}$ & aug-07 & 46.113 & 0.225 & nd & $2.19 \pm 0.42$ & nd & nd & 1.19 & nd & nd & 243 & nd \\
\hline $\mathrm{Bv}$ & aug-07 & 52.136 & 0.415 & nd & $0.71 \pm 0.27$ & nd & nd & 0.34 & nd & nd & 42.5 & nd \\
\hline Bvi & aug-07 & 35.622 & 0.123 & - & nd & $0.41 \pm 0.06$ & - & nd & 0.28 & - & nd & 82.4 \\
\hline $\mathrm{Gz}$ & aug-07 & 56.102 & 0.405 & nd & $1.57 \pm 0.26$ & $0.24 \pm 0.13$ & nd & 0.70 & 0.11 & nd & 97.3 & 15.1 \\
\hline $\mathrm{Mg}$ & aug-07 & 48.116 & 0.425 & $0.58 \pm 0.06$ & $2.40 \pm 0.39$ & $0.37 \pm 0.01$ & 0.30 & 1.24 & 0.19 & 34.4 & 141 & 21.6 \\
\hline $\mathrm{Sm}$ & aug-07 & 51.522 & 0.025 & - & nd & $0.33 \pm 0.24$ & - & nd & 0.16 & - & nd & 325 \\
\hline To & aug-07 & 55.018 & 0.212 & nd & - & $0.21 \pm 0.12$ & nd & - & 0.09 & nd & - & 24.4 \\
\hline IDL & aug-07 & & & 0.73 & 0.85 & 0.50 & & & & & & \\
\hline $\mathrm{Bm}$ & sep-07 & 45.766 & 0.281 & - & $3.40 \pm 0.89$ & nd & - & 1.86 & nd & - & 303 & nd \\
\hline $\mathrm{Bv}$ & sep-07 & 47.878 & 0.399 & nd & $2.49 \pm 1.19$ & nd & nd & 1.30 & nd & nd & 156 & nd \\
\hline Bvi & sep-07 & 49.872 & 0.307 & - & $1.50 \pm 0.07$ & nd & - & 0.75 & nd & - & 122 & nd \\
\hline $\mathrm{Gz}$ & sep-07 & 50.247 & 0.648 & $2.61 \pm 0.08$ & $1.79 \pm 0.99$ & nd & 1.30 & 0.89 & nd & 101 & 69.0 & nd \\
\hline $\mathrm{Mg}$ & sep-07 & 51.740 & 0.415 & nd & $3.29 \pm 0.52$ & nd & nd & 1.59 & nd & nd & 198 & nd \\
\hline $\mathrm{Sm}$ & sep-07 & 46.344 & 0.126 & - & nd & nd & - & nd & nd & - & nd & nd \\
\hline To & sep-07 & 46.557 & 0.083 & nd & $0.73 \pm 1.09$ & nd & nd & 0.39 & nd & nd & 220 & nd \\
\hline$I D L$ & sep-07 & & & 0.62 & 1.47 & 0.78 & & & & & & \\
\hline
\end{tabular}

estimated at approximately $32 \mathrm{~cm}^{2}$. Leaf collecting is not expected to be selective with respect to the traffic-borne PGE pollution, and in fact, ordinary soil can stick on the leaves as well, particularly in extra-urban and/or open locations. Thus, in those cases, the PGE result is somewhat more diluted than elsewhere and, in this respect, the sites of $\mathrm{Gz}$ and Bvi are found to be remarkable. The total collected particulate matter reached particularly high levels in dry periods, up to $40 \mathrm{mg}$ per $1 \mathrm{~g}$ of leaves or approximately $1.25 \mathrm{mg} / \mathrm{cm}^{2}$ (see jul-07, Bvi). In Fig. 2, the monthly PM depositions (in mg of PM per g of leaf), averaged over the four traffic exposed locations (with Bvi too), are compared with the rain records in Varese (Centro Geofisico Prealpino, http://www.astrogeo.va.it/statisti/statmet.htm). In fact, the highest PM loadings were observed in the unusually dry period of January-April 2007 (with only $155 \mathrm{~mm}$ of rain, as compared with the expected $418 \mathrm{~mm}$ averaged on 30 years of records) and in July (44 $\mathrm{mm}$ as compared with the expected 102).
Heavy atmospheric precipitations can scale down the amounts of collected PM 2-3-fold, as observed in the sampling made on May 31, 2007, just 3 days after a period of unusually heavy rain $(68 \mathrm{~mm}$ in $24 \mathrm{~h}$, approximately $200 \mathrm{~mm}$ in the month), and in August-September, where a total of $439 \mathrm{~mm}$ of rain (300 expected) led to poor dust collection and levels of Pt and Rh mostly under the IDL. Of course, these results are not unexpected and similar relationships have already been reported. For example, a connection between the road-dust PGE levels and rainfall was evidenced in a survey made in Perth, West Australia (Whiteley 2005).

\subsection{Influence of the location}

It can be seen in Table 2 that over the period JanuarySeptember 2007, in the two 'clean' locations at Sacro Monte (Sm) and Villa Toeplitz (To), we got values essentially under the detection limits. Particularly, minimal 


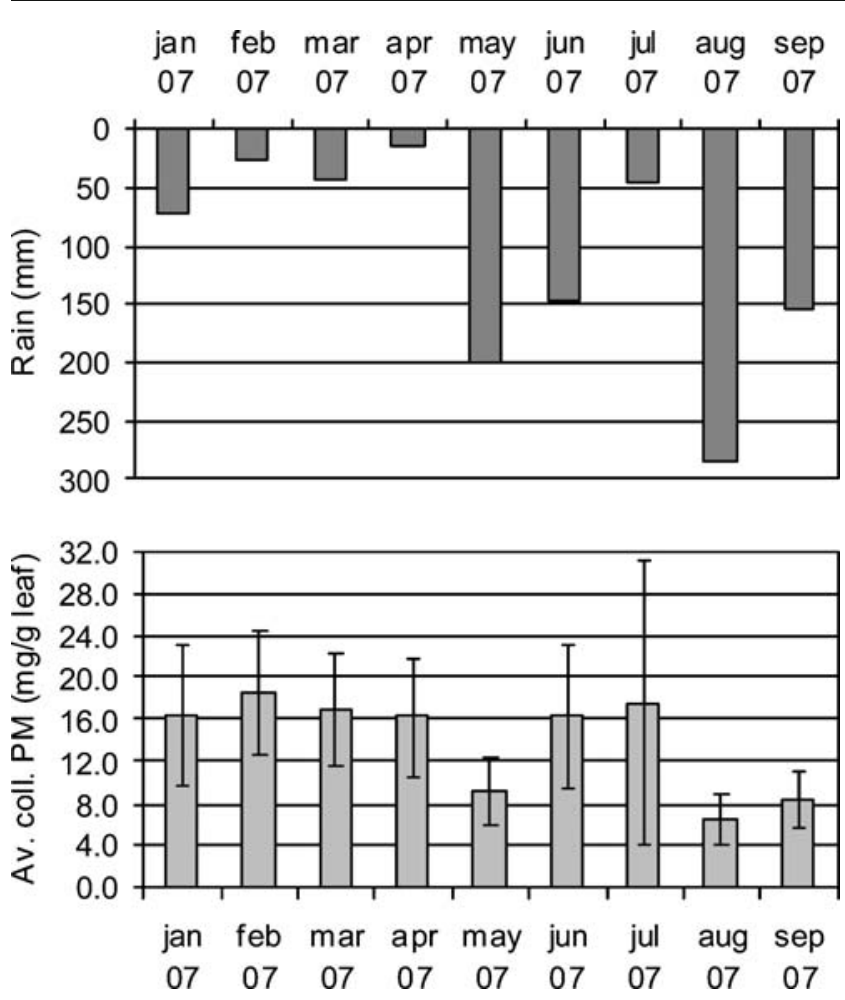

Fig. 2 Monthly PM depositions (in $\mathrm{mg}$ per $1 \mathrm{~g}$ of leaf) averaged on the four traffic exposed sites, compared with the Varese raining records

and yet significant (i.e., >IDL) amounts of palladium and rhodium were observed in Sm just once (in April and May, respectively), while the two metals are just slightly more recurrent in To; in both sites, platinum went mostly undetected. The chart in Fig. 3 reports the median values calculated for each site; these values appear to us to be more realistic indicators of the local pollution than the means. One thing is quite remarkable: platinum never

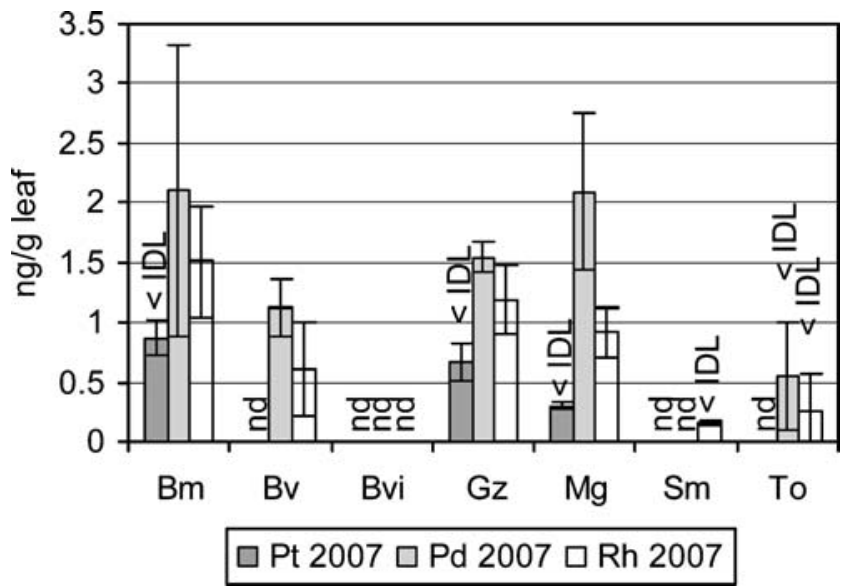

Fig. 3 The Pt, Pd, and Rh depositions (ng per $1 \mathrm{~g}$ of leaf) representative of the local pollution in the sampling sites. The reported values are the median calculated over the period January-September 2007 reaches significant (>IDL) values. The three PGEs reach the highest levels at $\mathrm{Bm}, \mathrm{Bv}, \mathrm{Gz}$, and $\mathrm{Mg}$, five to ten times that which can be found in the other locations, a clear indication that the pollution strictly depends on the distance from the traffic fluxes and their intensity. This correlation was particularly evident in sampling site Bvi (inside via Valmorea, approximately $20 \mathrm{~m}$ from the main traffic flux close to $\mathrm{Bv}$ ), with the three PGEs essentially being undetected. Similarly, in the 2004-2005 period, the PM deposition in Bvi was found, on average, to have $20-25 \%$ of that found in the $\mathrm{Bv}$ exposed location.

It must also be said that, in the $\mathrm{Bv}$ site, for a few months in 2004-2005, we could find evidence that the samplings made close to the ground (less than $0.5 \mathrm{~m}$ ) showed an average metal content $35-45 \%$ higher with respect to the samplings made approximately $2 \mathrm{~m}$ high. These results are consistent with a dry deposition, with relatively low mobility from the pollution source.

\subsubsection{Composition of the PM: a comparison with the 2004-2005 results}

As seen above, the amount of PGEs collected by the leaves in a location can be taken as an index of its specific pollution. However, since the collected PM can also greatly change in dependence of the atmospheric precipitations, it is convenient considering the results with reference to the composition of the PM itself. Thus, the PGE's contents of the particulate, in $n g\left(10^{-9} \mathrm{~g}\right)$ per $1 \mathrm{~g}$ of PM, are reported in Table 2 and illustrated in Fig. 4.

Palladium is clearly the most abundant of the three PGEs and it can presently be up to 3-3.5 times as high ( $w / w)$ as that of the platinum (approximately $6-7 \mathrm{~mol} / \mathrm{mol}$ ). This is quite remarkable because only a few years ago the

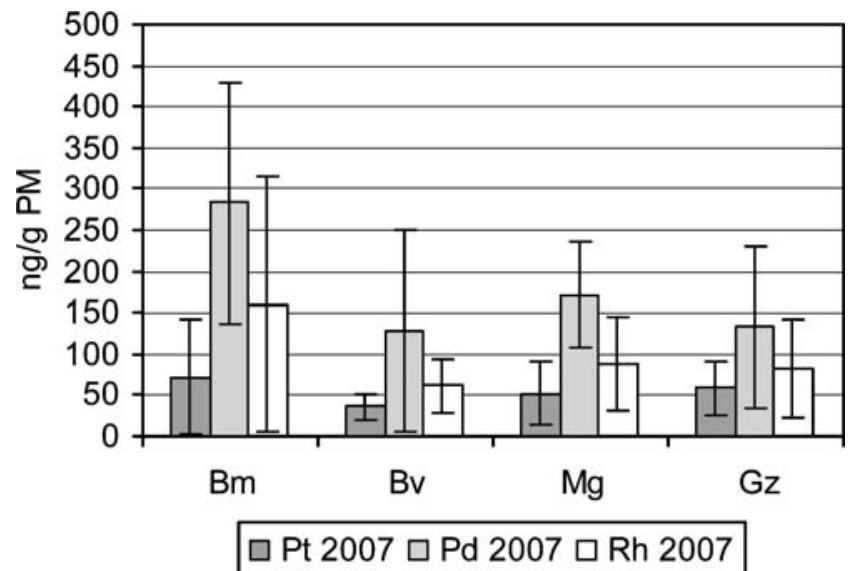

Fig. $4 \mathrm{Pt}$, Pd, and Rh content of the particulate (ng per $1 \mathrm{~g} \mathrm{PM}$ ) in the four traffic exposed locations, averaged on the period JanuarySeptember 2007 

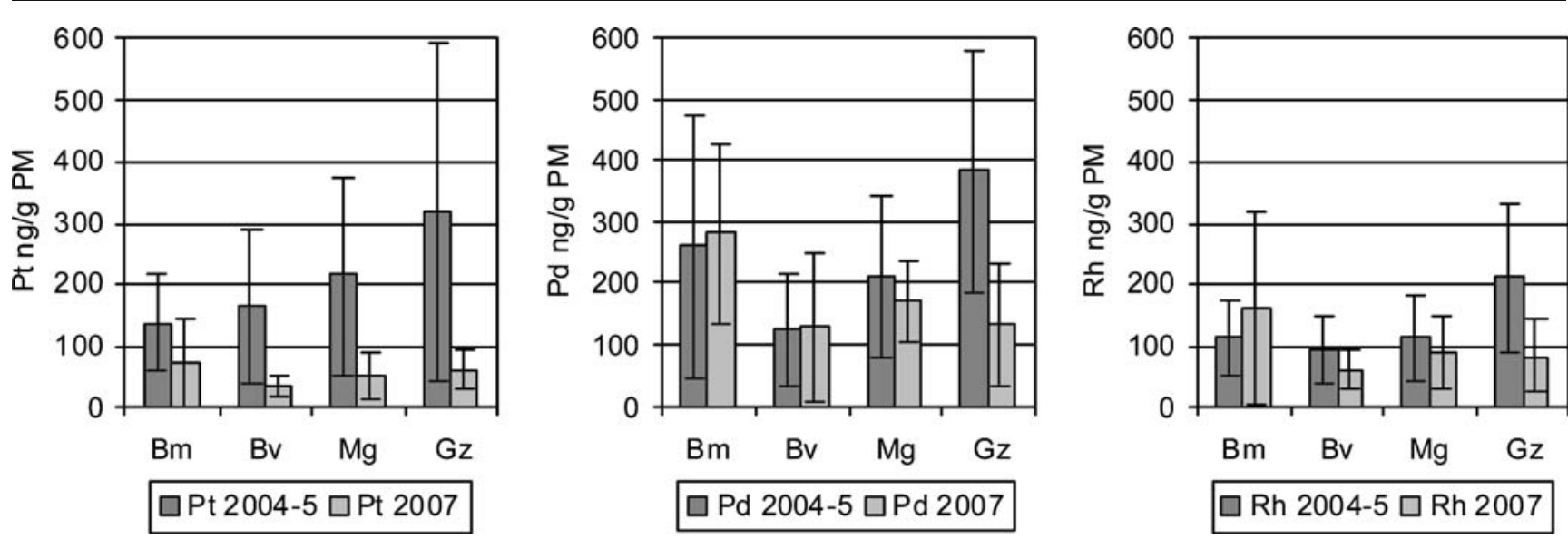

Fig. 5 The changing PGEs content of the particulate in the four selected locations (ng per 1 g PM) from 2004-2005 to 2007, averaged over the two periods

relationship between $\mathrm{Pt}$ and $\mathrm{Pd}$ concentrations was reversed; in fact, $\mathrm{Pt} / \mathrm{Pd} w / w$ ratios ranging between 10 and 5 were found in various polluted matrices such as grass, soil, and road dust (Helmers et al. 1998), consistently with catalytic converters operating at that time, based essentially on Pt-Rh or Pt only. However, it has to be pointed out that in the USA (San Diego, CA) a somewhat different situation has been emerging since 1986, with $\mathrm{Pt} / \mathrm{Pd}$ ratios as low as 2.5 , reflecting the use of new catalytic converters (Hodge and Stallard 1986). In this respect, the $\mathrm{Pt} / \mathrm{Pd} w / w$ ratio of 2.14 characterizing the abovementioned NIST standard from used auto catalysts (see Section 2.1.2) is also indicative.

With reference to Figs. 5 and 6 , we may say that the relative composition of the particulate appeared to be comparable in all the four sites in 2004-2005, within approximately $20 \%$ of variance. In fact, the $\mathrm{Pt} / \mathrm{Rh}$ and $\mathrm{Pd} /$ $\mathrm{Rh} w / w$ ratios, averaged on the four sites, resulted in $1.59 \pm$ 0.30 and $1.84 \pm 0.41$, respectively. The most relevant result of the 2007 survey, with respect to the 2004-2005 one, is the dramatic, generalized reduction of the relative (with respect to Rh) PM platinum content. The drop was more important in the three urban sites of $\mathrm{Bm}, \mathrm{Bv}$, and $\mathrm{Mg}$, with

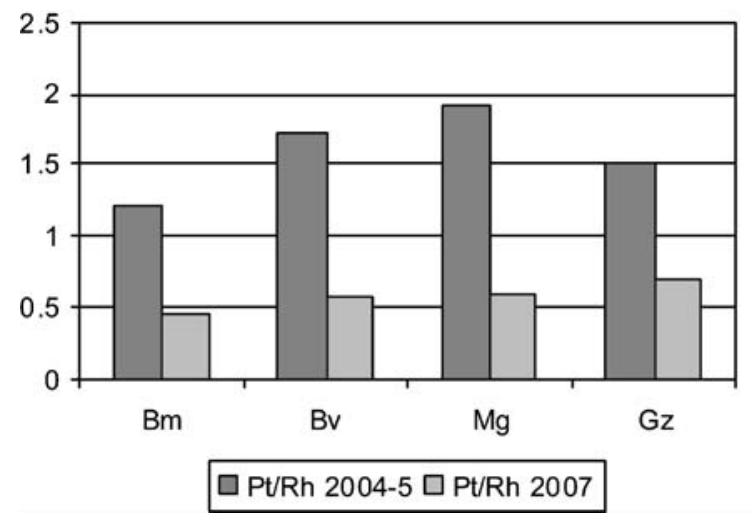

an average $\mathrm{Pt} / \mathrm{Rh}$ ratio of $0.54 \pm 0.08$, approximately $1 / 3$ of the previous ones, while the relative Pt content was reduced to about half in $\mathrm{Gz}$ (Pt/Rh ratio of 0.71$)$. The peculiar traffic of $\mathrm{Gz}$, with a high number of heavy trucks, may explain this difference: these diesel-fueled vehicles still have catalysts mostly based only on platinum and, very likely, this somewhat counterbalances a general tendency towards a reduction of the Pt levels. In 2007, the relative palladium content showed the same average value $(\mathrm{Pd} / \mathrm{Rh}=1.85 \pm$ 0.21) as found in 2004-2005. However, in all cases, the results are quite far from the 'classical' $\mathrm{Pt} / \mathrm{Rh} w / w$ ratio of $5: 1$ that was a common marker of the traffic pollution just a few years ago (Petrucci et al. 2000; Schramel et al. 2000; Gomez et al. 2002; Lesniewska et al. 2004; Whiteley 2005).

\section{Conclusions}

Comparison of the 2004-2005 and 2007 data gives a significant insight into 2 years of evolution in catalyst design and automotive trends. The changes can be explained with two recent occurrences: (1) the increasing

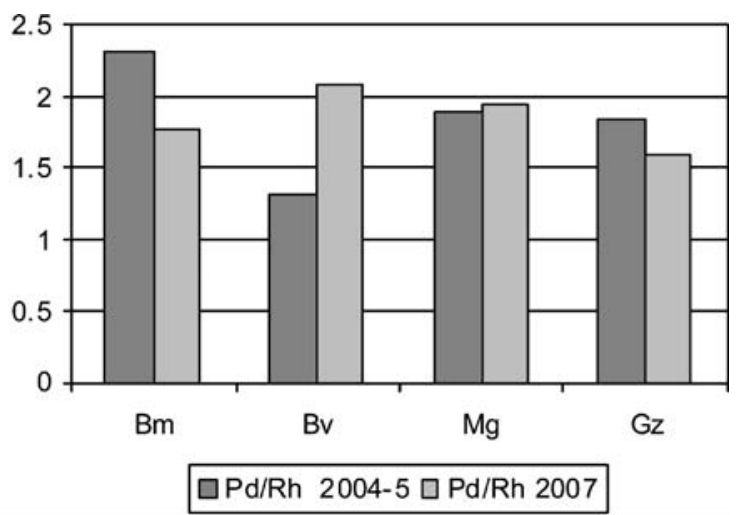

Fig. $6 \mathrm{The} \mathrm{Pt} / \mathrm{Rh}$ and $\mathrm{Pd} / \mathrm{Rh} w / w$ ratios, averaged over the two periods $2004-2005$ and 2007 
diffusion of cars with a diesel engine (Automobile Club d'Italia, ACI 2008), whose catalysts are made up without any rhodium, and (2) the latest changes in catalyst technology that, based also on the vicar role played by the two metals, tend to replace the high-priced platinum with the cheaper palladium. Our results can somehow be compared with those reported in a recent report about changes in PGE concentrations, along a major highway in Germany, from 1994 to 2004 (Zereini et al. 2007); in this important study, a dramatic surge of the Pd levels has been demonstrated, a 15 -fold increase over the 10-year period, while the levels of Pt and Rh were only 2 and 1.6 times higher.

About our survey and the supporting procedure, we may say that the leaves of P. laurus cerasus are efficient PM collectors and the analysis of the road-side dust stuck on foliage is a good indicator of traffic-borne pollution; the collected PGE amounts strictly depend on the distance from the traffic fluxes and their intensity. The proposed analytical procedure, restricted to the leaf dust recovered with an efficient washing procedure, greatly reduces the matrix effect and does not require a prior preconcentration and/or matrix separation. Therefore, it is simple and reliable and can be easily performed with a graphite furnace-equipped atomic absorption spectrophotometer (GFAA), overcoming the problems occurring in Pd quantification with ICP-MS (Moldovan 2007). We suggest that this dust recovery procedure can be extended to other broad-leaved plants exposed to vehicular traffic (Hodge and Stallard 1986).

Acknowledgements The research was carried out with FAR (Fondo di Ateneo per la Ricerca) of Università degli Sudi dell'Insubria. We are indebted to Alberto Vianelli for helpful suggestions.

\section{References}

Automobile Club d'Italia (ACI) (2008) According to recent reports, in Varese province new cars with a diesel engine tend to reach in number those relying on gasoline, following an Italian and European trend. Thus, diesel equipped cars that amounted to $32 \%$ in 2001-2002, increased to $44 \%$ in 2006-2007

Bikhazi AB, Salameh A, El-Kasti MM, Awar RA (1995) Comparative nephrotoxic effects of cis-platinum(II), cis-palladium(II) and cisrhodium(III) metal coordination compounds in rat kidneys. Comp Biochem Physiol 111(3):423-427

Botrè C, Tosi M, Mazzei F, Bocca B, Petrucci F, Alimonti A (2007) Automotive catalytic converters and environmental pollution: role of the platinum group elements in the redox reactions and free radicals production. Int J Environ Health 1(1):142-152

Centro Geofisico Prealpino, records are available at: http://www. astrogeo.va.it/statisti/statmet.htm

Comune di Varese, Ufficio Tecnico Traffico e Trasporti (2003) PIANO URBANO DEL TRAFFICO - quadro conoscitivo e strategie d'intervento, quaderno N.1, Gennaio 2003
Gebel T, Lantzsch H, Pleßow K, Dunkelberg H (1997) Genotoxicity of platinum and palladium compounds in human and bacterial cells. Genetic Toxicol Environ Mutagenesis 389(2-3):183-190

Gomez B, Palacios MA, Gomez M, Sanchez JL, Morrison G, Rauch S, McLeod C, Ma R, Caroli S, Alimonti A, Petrucci F, Bocca B, Schramel P, Zischka M, Petterson C, Wass U (2002) Levels and risk assessment for humans and ecosystems of platinum-group elements in the airborne particles and road dust of some European cities. Sci Total Environ 299:1-19

Heck RM, Farrauto RJ (2001) Automobile exhaust catalysts. Appl Catalysis A: General 221:443-457

Helmers E, Schwarzer M, Schuster M (1998) Comparison of palladium and platinum in environmental matrices. Environ Sci Pollut Res 5:44-50

Hodge VF, Stallard MO (1986) Platinum and palladium in roadside dust. Environ Sci Technol 20(10):1058-1060

Lesniewska BA, Godlewska-Zyłkiewicz B, Bocca B, Caimi S, Caroli S, Hulanicki A (2004) Platinum, palladium and rhodium content in road dust, tunnel dust and common grass in Bialystok area (Poland): a pilot study. Sci Total Environ 321:93-104

Merget R, Rosner G (2001) Evaluation of the health risk of platinum group metals emitted from automotive catalytic converters. Sci Total Environ 270:165-173

Moldovan M (2007) Origin and fate of platinum group elements in the environment. Anal Bioanal Chem 388:537-540

Moldovan M, Palacios MA, Gómez MM, Morrison G, Rauch S, McLeod C, Ma R, Caroli S, Alimonti A, Petrucci F, Bocca B, Schramel P, Zischka M, Pettersson C, Wass U, Luna J, Saenz C, Santamaría J (2002) Environmental risk of particulate and soluble platinum group elements released from gasoline and diesel engine catalytic converters. Sci Total Environ 296:199-208

Moldovan M, Rauch S, Gómez PMA, Morrison GM (2001) Bioaccumulation of palladium, platinum and rhodium from urban particulates and sediments by the freshwater isopod Asellus aquaticus. Wat Res 35(17):4175-4183

Palacios MA, Gómez M, Moldovan M, Gómez B (2000) Assessment of environmental contamination risk by $\mathrm{Pt}, \mathrm{Rh}$ and $\mathrm{Pd}$ from automobile catalyst. Microchem J 67:105-113

Petrucci F, Bocca B, Alimonti A, Caroli S (2000) Determination of $\mathrm{Pd}$, Pt and $\mathrm{Rh}$ in airborne particulate and road dust by highresolution ICP-MS: a preliminary investigation of the emission from automotive catalysts in the urban area of Rome. J Anal At Spectrom 15(5):525-528

Provincia di Varese, Data available on-line at the official site of: http:// www.provincia.va.it/viabilita.htm

Schramel P, Zischka M, Muntau H, Stojanik B, Dams R, Gómez Gómez M, Ph Q (2000) Collaborative evaluation of the analytical state-of-the-art of platinum, palladium and rhodium determinations in road dust. J Environ Monit 2:443-446

Whiteley JD (2005) Seasonal variability of platinum, palladium and rhodium (PGE) in road dusts and roadside soils, Perth, Western Australia. Water Air Soil Pollut 160:77-93

Zereini F, Alt F (eds) (1999) Antropogenic platinum-group element emissions. Their impact on man and environment. Springer, Berlin

Zereini F, Wiseman C, Püttmann W (2007) Changes in palladium, platinum, and rhodium concentrations, and their spatial distribution in soils along a major highway in Germany from 1994 to 2004. Environ Sci Technol 41(2):451-456

Zimmerman S, Menzel CM, Stübenb D, Taraschewski H, Sures B (2003) Lipid solubility of the platinum group metals Pt, Pd and $\mathrm{Rh}$ in dependence on the presence of complexing agents. Environ Pollut 124(1):1-5 